\title{
Semantic Orientation of Sermons From the 1920s to 1980s _- Areas of Consistency and Variability
}

\author{
Denise A. D. Bedford \\ Kent State University, Kent Ohio, U.S.A
}

\begin{abstract}
Traditionally, the field of knowledge management has focused on knowledge that is created in work-related settings, in high profile organizations, and sectors which have high economic value. As the knowledge economy expands into all aspects of society, there is increased awareness of the value of understanding how people transfer knowledge in everyday contexts, beyond the formal work or business environment. Religious communities are "knowledge rich" in both foundational knowledge and beliefs and knowledge practices. To date, though, the knowledge management literature has not considered religion as an area of study or research. In 2011, researchers at Kent State University undertook exploratory research into the knowledge management practices of religious communities, specifically the use of language in sermons. Sermons are an important source of knowledge transfer and mobilization in religious communities. That research focused on the intentional and extensional language of sermons across nine religious denominations, including Evangelical Lutheran, Evangelical Baptist, Seventh Day Adventist, Catholic, Episcopalian, Methodist, Presbyterian, Congregational and Unitarian.
\end{abstract}

Keywords: semantic analysis, religious knowledge, religious sermons, automated categorization

\section{Introduction}

Traditionally, the field of knowledge management has focused on knowledge that is created in work-related settings, in high profile organizations, and sectors which have high economic value. As the knowledge economy expands into all aspects of society, there is increased awareness of the value of understanding how people transfer knowledge in everyday contexts, beyond the formal work or business environment. Knowledge management is relevant to all aspects of our lives and our economy in the 21st century. It is important for knowledge management professionals to extend their understanding beyond the Fortune 500 company or the high profile public sector organization.

Communication and language are essential elements of all stages of a knowledge life cycle. By the knowledge life cycle we mean all stages — from the discovery of a knowledge gap, to idea generation, to knowledge creation, mobilization, propagation, capture, management and preservation. Historically, language has received less attention from the knowledge management community. Language, in the form of semantics, though, receiving more attention from the knowledge sciences research community due to the popularization of semantic technologies and the increasing use of computational intelligence methods.

Religious communities are "knowledge rich" in both foundational knowledge and beliefs and knowledge

Denise A. D. Bedford, Ph.d., Goodyear Professor of Knowledge Management, Kent State University.

Correspondence concerning this article should be addressed to 1700 Brighton Dam Road, Brookeville MD, 20833. Email: dbedfor3@kent.edu. 
practices. A large portion of the population in any society participates in a religious community. Most religious or belief systems today have an explicit foundational knowledge and belief system, and a set of established practices for mobilizing and propagating (i.e., transferring or handing down) that knowledge across communities and over time. To date, though, the knowledge management literature has not considered religion as an area of study or research. What research exists on knowledge management in religion derives from the work in the theological community. This prevents both a gap and an opportunity.

In 2011, researchers at Kent State University (Bedford, 2011) undertook exploratory research into the knowledge management practices of religious communities, specifically into the language of sermons. Sermons are an important source of knowledge transfer and mobilization in religious communities. That research focused on the intentional and extensional language of sermons across nine religious denominations, including Evangelical Lutheran, Evangelical Baptist, Seventh Day Adventist, Catholic, Episcopalian, Methodist, Presbyterian, Congregational and Unitarian. The data set included sermons delivered from 2005 through 2011. The research results suggested that the intentional and extensional language used in sermons was balanced across all nine denominations. In addition, the research attempted to characterize the positive, negative and neutral emotion expressed in sermons.

This research extends the earlier work in two ways. First, it applies the analysis of intentional and extensional language to a historical collection of sermons_— sermons delivered from the 1920s through 1980s. Second, it applies a more rigorous and widely accepted approach to analyzing the emotional intensity of language used in sermons. This research continues to leverage semantic analysis methods and technologies, given the strengths demonstrated in the earlier work.

\section{Research Context and Questions}

This research continues the focus on sermons delivered within the Christian religious community. While there are common elements to all belief systems, we believe that common knowledge practices are more likely to be found within a single system. The Christian religion provides us with a well-defined knowledge foundation and set of beliefs. It also provides us with a common knowledge practice —use of weekly sermons. A sermon is oration, a form of discourse generally delivered as a monologue by clergy or other recognized religious experts (Ortberg, 2007). Sermons are effective methods of mobilizing and transferring knowledge by and among religious leaders and religious community members. Sermons are preached- - using language which is chosen to effectively instruct the religious community, and to convey theological, religious or moral knowledge. The purpose of a sermon may address a wide range of issues, including general religious issues and topics, conversion efforts, narratives which tell stories and convey morals, and interpretations of current events.

This research extends the earlier work in through exploration of three questions:

Question 1: Does the balance of extensional and intentional nature of language used in sermons hold as we move back in time to the early 20th century?

Question 2: Can we detect the emotional intensity of language in sermons?

Question 3: If so, does it exhibit the same balanced behavior as other language characteristics?

\section{Research Methodology}

\section{Research Question 1: Research Metrics}

This research focuses on the use of intentional and extensional language in sermons as an indication of 
different structures and approaches to conveying knowledge and ideas (Korzybski, 1938). Generally speaking, semanticists characterize intentional language as more abstract and conceptual, whereas extensional language is more concrete and enumerative of real examples and properties. In the context of religion, intentional language may tend to be more dogmatic but also have a closer resemblance to narrative and storytelling. Conversely, extensional language may tend to be more balanced and qualified and more characteristic of logical arguments and rationality.

An example of early work in semantics came in 1940 when Raymond McLaughlin (McLaughlin, 1940) translated general ideas of intentional and extensional into concrete, observable linguistic criteria. In an era many years before the widespread availability of computers, McLaughlin applied his characteristics manually to sermons from two preachers: Harry Emerson Fosdick, pastor of the Riverside Church of New York City, a liberal pastor of what is even today considered to be a liberal religious denomination, and the well-known fundamentalist mass evangelist preacher, Oral Roberts. McLaughlin found 15 sermons from each pastor and manually analyzed their language for frequency of occurrence of intentional and extensional characteristics. McLaughlin's criteria are described in Table 1.

Table 1

McLaughlin's Semantic Criteria Interpreted for Semantic Analysis

\begin{tabular}{|c|c|c|}
\hline Semantic type & Semantic criteria & Semantic representation \\
\hline \multicolumn{3}{|l|}{ Intentional criteria } \\
\hline Allness language & $\begin{array}{l}\text { Allness terms as represented by such } \\
\text { terms as all, every, entire, whole, } \\
\text { none... }\end{array}$ & $\begin{array}{l}\text { Two hundred concepts comprised largely of single work } \\
\text { adjectives and adverbs derived from common word lists, } \\
\text { dictionaries, glossaries and thesauri }\end{array}$ \\
\hline Superlative language & $\begin{array}{l}\text { Superlative terms such as best, worst, } \\
\text { most, least, only, matchless }\end{array}$ & $\begin{array}{l}\text { Two thousand and sixty one concepts derived from single } \\
\text { word adjectives and compound adjectival phrase with } \\
\text { superlative connotations derived from common word lists, } \\
\text { dictionaries, glossaries and thesauri }\end{array}$ \\
\hline Two-valued language & $\begin{array}{l}\text { Two-valued terms such as either:or, if: } \\
\text { when, if: not,... }\end{array}$ & $\begin{array}{l}\text { Thirty two concepts representing individual and combined } \\
\text { concepts representing multivalve contexts }\end{array}$ \\
\hline $\begin{array}{l}\text { Identification-prec } \\
\text { language }\end{array}$ & $\begin{array}{l}\text { "Is" of statements which represented } \\
\text { identification of objects. "Is" of as } \\
\text { predication terms such as "roses are } \\
\text { beautiful" }\end{array}$ & $\begin{array}{l}\text { Thirty nine concepts which represented both identification } \\
\text { and predication semantics as these are typically difficult to } \\
\text { distinguish by humans and are more challenging to interpret } \\
\text { at the machine level }\end{array}$ \\
\hline \multicolumn{3}{|l|}{ Extensional criteria } \\
\hline Comparative language & $\begin{array}{l}\text { Comparative terms such as higher, } \\
\text { lower, more, less... }\end{array}$ & ing single and \\
\hline Quantitative language & $\begin{array}{l}\text { Quantifying terms or precise numerical } \\
\text { designations such as } 60 \text {, sixty, second... }\end{array}$ & $\begin{array}{l}\text { Ninety and seven concepts of both alphabetical and } \\
\text { numerical characterizations of quantity }\end{array}$ \\
\hline Conditional language & $\begin{array}{l}\text { Conditional terms such as if, but, except, } \\
\text { perhaps, unless... }\end{array}$ & $\begin{array}{l}\text { One hundred and fourteen concepts representing single and } \\
\text { multi-word conditional terms derived largely from thesauri, } \\
\text { word lists, glossaries }\end{array}$ \\
\hline \begin{tabular}{|l|} 
Consciousness \\
projection language
\end{tabular} & $\begin{array}{l}\text { Consciousness of projection terms such } \\
\text { as seems, appears, in my opinion... }\end{array}$ & $\begin{array}{l}\text { Fifty three concepts representing single and multi-word } \\
\text { terms derived largely from thesauri and word lists }\end{array}$ \\
\hline $\begin{array}{l}\text { Pseudo-quantifying } \\
\text { language }\end{array}$ & $\begin{array}{l}\text { Pseudo-quantifying terms or terms that } \\
\text { loosely represent the idea of amount, } \\
\text { size such as many, much, few, lots... }\end{array}$ & $\begin{array}{l}\text { single and multi-word } \\
\text { word lists }\end{array}$ \\
\hline
\end{tabular}

Using manual semantic analysis of the two collections of sermons and through machine-supported semantic analysis of sermons from nine denominations, McLaughlin and Bedford reached the same conclusions. Sermons are characterized by balance rather than variation in the use of intentional and extensional language. The research reported in this paper leverages the same methods and metrics to a collection of historical sermons. 


\section{Research Question 2: Metrics for Emotional Intensity of Language in Sermons}

The earlier research (Bedford, 2011) used a simple positive and negative semantic profile to evaluate the emotional orientation of sermons. This metric was not sufficient compared to other more widely validated and accepted metrics in the psychology and psychiatric disciplines. Several other metrics were considered for this research. First, Boder (Boder, 1940) and Busemann (Busemann, 1925) use a simple ration of adjectives to verbs as predicate values to gauge the emotional intensity of language. This is an important metric, though it is incomplete according to experts in the fields of psychology and psychiatry (Gottschalk, 1955; Gottschalk, 1974; Gottschalk, 1995; Gottschalk, Hausmann, \& Brown, 1975; Jarvis, 1949; Kaplan, 1943; Malla, 1991; Viney, 1981, 1983). The Gottschalk-Gleser Content Analysis Method for measuring the magnitude of various psychobiological states and traits was found to be the most widely tested and adopted method for analyzing the emotional intensity of communication content (Gleser, 1979; Gottschalk \& Gleser, 1969; Gottschalk, 1974; Gottschalk, 1999; Gottschalk \&Bechtel, 1982; Gottschalk\& Bechtel, 1989, 1995).

The Gottschalk-Gleser approach uses both frequency and non-frequency characteristics of language to assess intensity. The methodology assigns differential weights to semantic and linguistic cues conveying the magnitude of subjective experiences. It further uses a series of weighted thematic categories for each psychological criterion. The methodology draws from behavioral and conditioning theory, psychoanalytic clinic theory and linguistic theory. Weights are initially assigned on the basis of clinical psychoanalytic theory and experience. Linguistic lexical features similar to those used by Boder and Busemann are included as indicators of the magnitude of the psychological state and contribute further to the weighting. This method was developed to address the needs of diagnosticians and therapists who use speech as a major source of information.

We adopt the definition of emotion or affects expressed by Gottschalk and Gleser (Gottschalk Gleser, 1969): “... qualitative feelings of varying intensity about which the depending on the relative amounts of awareness he has about these feelings and drive states”. Consistent with this characterization, we do not differentiate between affects, emotions and feeling states. Drawing from this foundational work, we adopt four of Gottschalk and Gleser's models which are pertinent to our interest in emotional intensity. The four include: (1) Anxiety (Gottschalk Gleser, 1969); (2) Hostility Externally Expressed (Gottschalk Gleser, 1969); (3) Hostility Internally Expressed (Gottschalk Gleser, 1969); and (4) Hope (Gottschalk, 1974). The models have been widely tested through extensive empirical research dating back to the late 1960s. The definition and focus of each of the criteria is described in Table 2.

Table 2

Indicators of Emotional Intensity

\begin{tabular}{|l|l|}
\hline Emotional intensity criteria & Scalar representation \\
\hline Anxiety & $\begin{array}{l}\text { Anxiety scale is classified into six subtypes: death, mutilation, separation, guilt, shame, and } \\
\text { diffuse or non-specific anxiety. }\end{array}$ \\
\hline Hostility directed outward & $\begin{array}{l}\text { This scale measures the intensity of adversely critical, angry, assaultive, asocial impulses and } \\
\text { drives towards objects outside oneself. }\end{array}$ \\
\hline Hostility directed inward & $\begin{array}{l}\text { This scale measures degrees of self-hate and self-criticisms and, to some extent, feelings of } \\
\text { anxious depression and masochism. }\end{array}$ \\
\hline Hope & $\begin{array}{l}\text { This scale measures the intensity of the optimism that a favorable outcome is likely to occur, } \\
\text { not only in one's personal earthly activities, but also to cosmic phenomena and even in } \\
\text { spiritual or imaginary events. Scale measures outcomes that lead to human survival, } \\
\text { preservation or enhancement of health, the welfare or constructive achievement of the self or } \\
\text { any of mankind. }\end{array}$ \\
\hline
\end{tabular}




\section{Research Methodology}

Semantic analysis research methods are well suited to the analysis of language used in sermons. Semantic analysis may be performed manually by humans reading and marking text, or using semantic analysis technologies. Manual analysis and scoring of metrics for all research questions is labor intensive and time consuming. Manual approaches do not scale and as a result limit the size of the data set that can be analyzed. As a result, they may produce unreliable results. Furthermore, human interpretation of the metrics has been found to lead to variation and performance concerns (Gottschalk Gleser, 1963). Semantic analysis technologies which leverage a deep understanding of natural language including language-specific dictionaries, grammatical rules and part of speech tagging, and morphological rules can be configured and trained to analyze content as would humans using a manual approach. When properly configured and engineered with embedded human knowledge, semantic analysis technologies have been observed to produce as, or more, objective results than those produced manually through human analysis.

For these reasons, two semantic technologies were selected to support data processing. The first technology is the SAS Content Categorization Suite. This technology was used to construct nine research profiles to support the analysis of use of intentional and extensional language. This technology supported the analysis of sermons from 2005 to 2011, where it proved to be both effective and reliable. A full description of the nine profiles is available for review (Bedford, 2011). Full profiles can be obtained from the author upon request. A second technology, GB Software, was used to conduct the analysis of emotional intensity. Each technology was configured to address the research metrics.

A three-step methodology was applied to all 379 sermons in the data set (see Figure 1). The first step involved the construction of the semantic profile to represent the research metrics. Four profiles were constructed to represent the use of Intentional Language. Five profiles were constructed to represent the use of Extensional Language. Four profiles were leveraged to represent the emotional intensity of the language in the sermons.

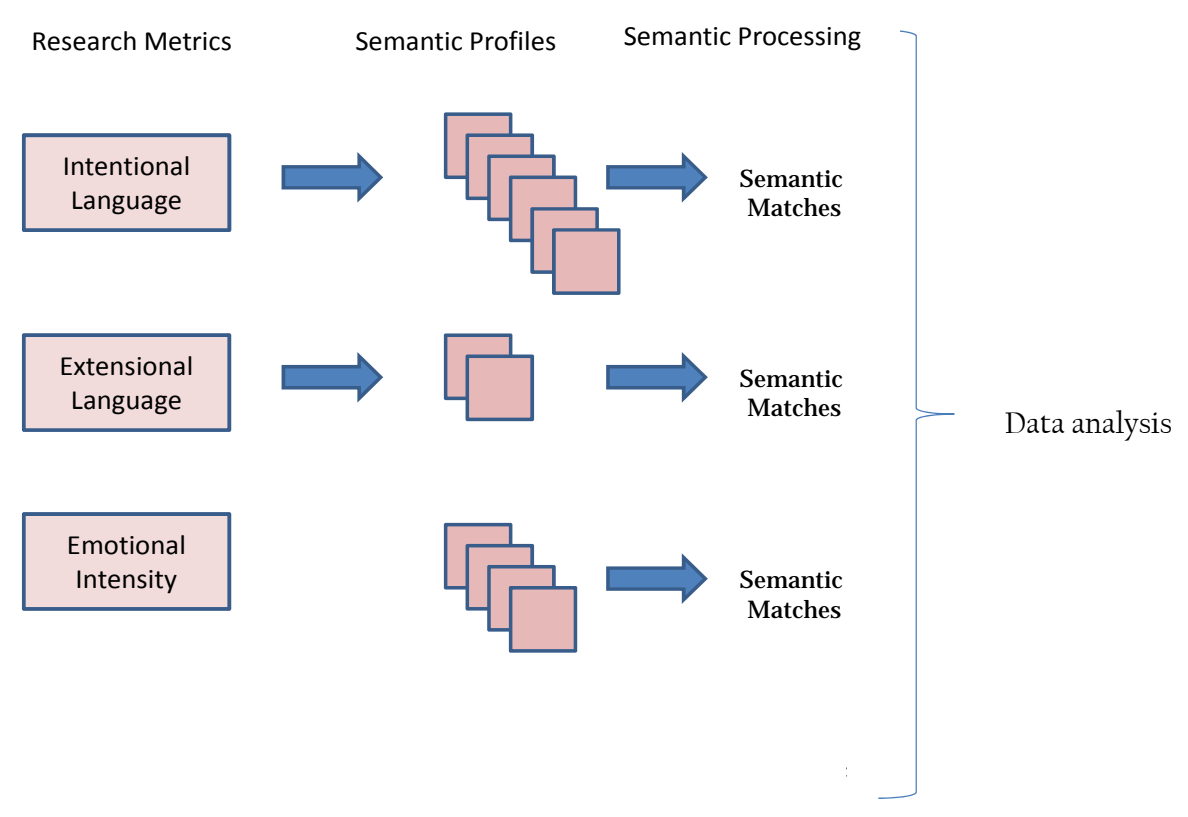

Figure 1. Three step semantic analysis research methodology. 
The first step involves creating a semantic index of each sermon document. This involves part of speech (POS) tagging of each word in the document. This semantic index is then used as a baseline for further semantic analysis. The results of this step are generally internal to the semantic application and invisible to the researcher.

The second step involves applying the profile to each and every sermon in the test collection. In the case of the analysis of intentional and extensional language use, this involved analyzing each of the 379 sermons against the nine SAS/Content Categorization Suite profiles. In the case of the analysis of emotional intensity, the Gottschalk-Gleser scalar models were applied to each sermon. Data for each metric was collected and added to the data tables for further analysis. In the third and final step, the research data was analyzed for patterns within and across time periods.

The SAS/Content Categorization Suite measured each sermon against a 50\% threshold. Sermons were reported to have failed or passed the 50\% "goodness of fit" threshold. The threshold is based on the number of pre-defined concepts and the rate of frequency with which they were found in the document. The threshold was established by the researcher to represent the minimal level of match of the content to the concepts and rules. The research determined the percentage of the sermons in a data set that passed and failed the threshold (Figure 2). The $50 \%$ threshold of occurrences was defined consistently with what a person might expect as a strong match to the specifications for each criterion. This is a fairly high threshold to achieve but the researcher wanted to set a high bar for the content.

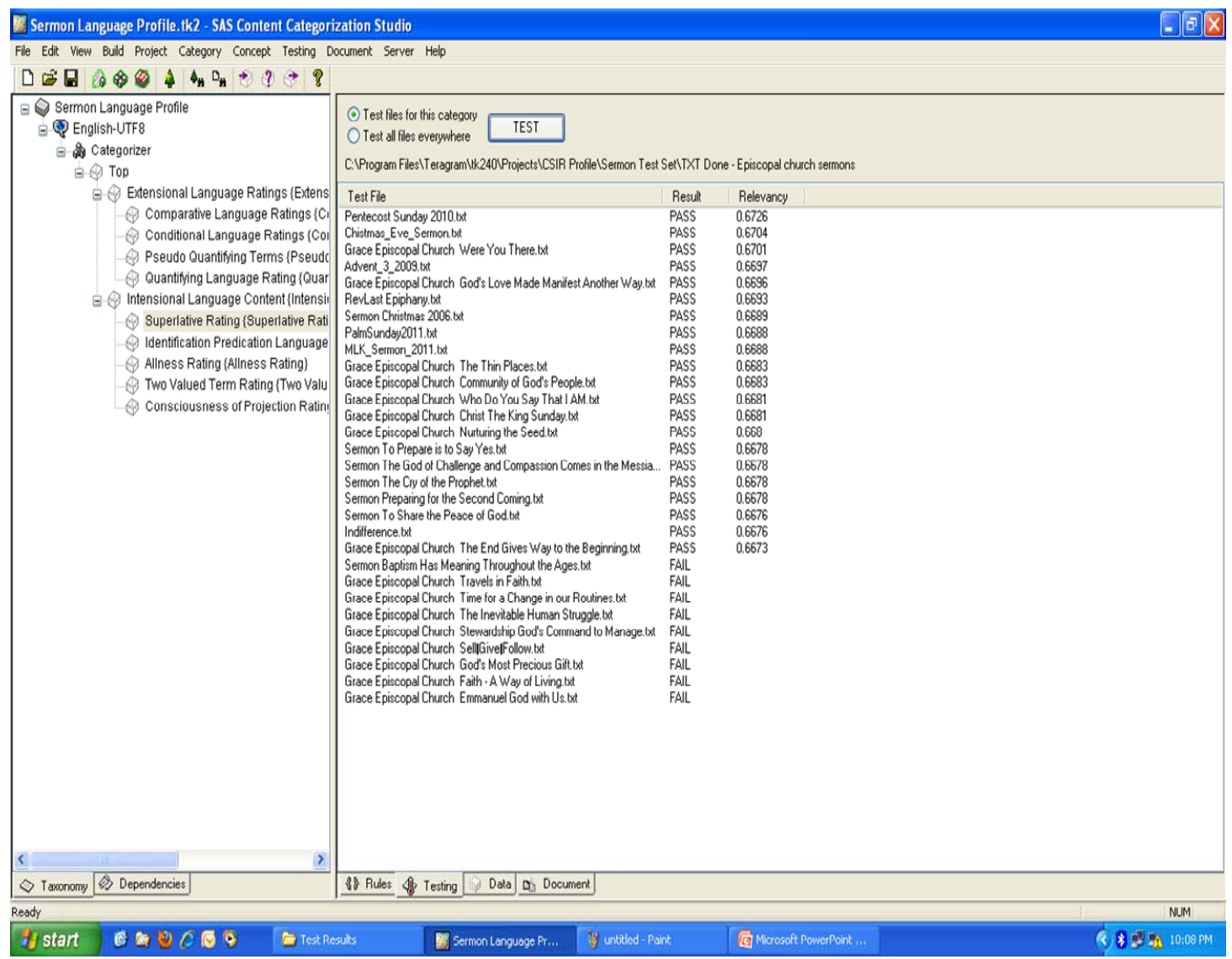

Figure 2. Semantic analysis threshold results for "Superlative” terms. 
Scores were generated by the GB Software for each of the four emotional criteria. The data output provided a raw subscale score, a corrected human score, and an interpretation of rating for each of the four criteria. Table 3 provides a sample data output for Anxiety for a sermon in the 1920 data set. The full set of scores is presented in Table $7 \mathrm{a}$ and $7 \mathrm{~b})$.

Table3

Tabulation of Verbal Sample Coded for Anxiety

\begin{tabular}{lll}
\hline & Subscale Score SqRt(RS+1/2CF) & Human Score \\
\hline Death & 3.162 & 3.069 \\
Mutilation & 3.162 & 2.064 \\
Separation & 3.162 & 1.695 \\
Guilt & 3.162 & 2.998 \\
Shame & 3.162 & 2.978 \\
Diffuse & 3.162 & 2.778 \\
Result & 3.162 & 3.103 \\
\hline
\end{tabular}

Notes. * Word Count $=5$; ** Correction Factor (C.F.) $=20.000$.

Based on norms for white male adults, the score is moderately high for the Anxiety scale. It is between two and three standard deviations above the mean.

\section{Research Data Set and Collection}

The research reported in 2011 focused on sermons which were delivered from 2005 through 2011. The research reported in this paper focuses on sermons which were delivered from 1920 through 1980. Our goal was to collect a statistically significant number of sermons for each of the six decades, providing an equivalent base for comparison with the analysis conducted in 2011. We encountered three challenges in achieving this goal, including: (1) discovery of historical sermons; (2) availability in digital format for semantic processing; and (3) representation of religious denominations.

The first challenge we encountered was the simple availability of full text versions of sermons delivered from 1920 through 1990. Three reliable sources were used_— published collections of sermons in book form, publicly available church websites, and commercial databases of sermons (see Table 4). In collecting sermons, we also found a large number of audio sources. Unfortunately, a high quality domain specific transcription resource was not available to convert the digital audio to digital text. In addition, time constraints did not allow us to request permission to transcribe these collections.

Beginning from 1950 sermons are more widely available in all three sources. Our primary challenge in assembling a research data set was finding sermons that had been delivered in the 1920s, 1930s, and 1940s. Most sermons from this time frame were found in published book collections. The data set representing sermons delivered from 1920s through the 1940s is more limited. Interpretation of the results for these decades should be regarded with caution. Sermons delivered from 1950 through 1980 were more readily available in published books, denomination-specific collections and church websites.

The second challenge pertained to the original format of historical sermons. Sermons which were discovered in published in book form were transformed from print to digital format by a manual process of photocopying and optical character recognition (OCR) format. Sermons that were published to the web or downloaded from databases were converted to text format for semantic analysis. A total of 359 sermons were collected and digitized for semantic analysis. 
Table 4

Summary Description of Research Data Collection and Sources

\begin{tabular}{lll}
\hline Sermon date & Number of sermons & Data sources \\
\hline 1920 & 20 & Selected Web Sites; Published Books \\
1930 & 24 & Published Books \\
1940 & 12 & Web; Published Books; Sermon Databases \\
1950 & 72 & Web; Published Books; Sermon Databases \\
1960 & 91 & Web; Published Books; Sermon Databases \\
1970 & 82 & Web; Published Books; Sermon Databases \\
1980 & 59 & Web; Published Books; Sermon Databases \\
Total number of sermons & 359 & \\
\hline
\end{tabular}

The third challenge pertained to building a balanced representation of Christian denominations. Research reported in 2011 drew upon a data set which was representative of and well balanced across nine denominations. Achieving a comparable level of balance in the current data set was challenging. It was clear from the data collection effort that some denominations have devoted more time to digitizing and publishing archival sermons than others. The data set represents sermons from several denominations including: Baptist, Congregational, Methodist, Lutheran, Episcopalian, Catholic, and Unitarian.

In addition, the data set represents sermons delivered by over 50 clergy. Despite these limitations, a data set of 379 sermons was assembled. The full list of clergy and their denominations are available upon request from the author.

\section{Research Results}

\section{Expected Result for Question 1}

We expected the research to demonstrate balance in the use of both intentional and extensional language in sermons, to indicate a consistent pattern of use of intentional or extensional language depending regardless of the time at which it was delivered. We expect that rates of use will be consistent from 1920 to 2010.

Results were evaluated based on the number of sermons which achieved the minimum 50\% threshold set for each criteria (see Tables 5, 6). In addition, results examined the average Goodness of Fit rate for each of the nine criteria (see Tables 7, 8).

Table 5

Number of Sermons Achieving Minimum 50\% Threshold

\begin{tabular}{|c|c|c|c|c|c|c|c|c|}
\hline & \multicolumn{2}{|c|}{$1920 \mathrm{~s}$} & \multicolumn{2}{|r|}{$1930 \mathrm{~s}$} & \multicolumn{2}{|c|}{$1940 \mathrm{~s}$} & \multicolumn{2}{|c|}{ 1950s } \\
\hline & $\mathrm{N}=$ & $\begin{array}{l}\% \text { at } 50 \% \\
\text { Level }\end{array}$ & $\mathrm{N}=$ & $\begin{array}{l}\% \text { at } 50 \% \\
\text { Level }\end{array}$ & $\mathrm{N}=$ & $\begin{array}{l}\% \text { at } 50 \% \\
\text { Level }\end{array}$ & $\mathrm{N}=$ & $\begin{array}{l}\% \text { at } 50 \% \\
\text { Level }\end{array}$ \\
\hline \multicolumn{9}{|l|}{ Intentional language content } \\
\hline Superlative rating & 16 & $84.21 \%$ & 7 & $58.33 \%$ & 6 & $45.45 \%$ & 52 & $72 \%$ \\
\hline Identification predication language ratings & 19 & $100 \%$ & 12 & $100 \%$ & 11 & $100 \%$ & 72 & $100 \%$ \\
\hline Allness rating & 18 & $94.73 \%$ & 12 & $100 \%$ & 11 & $100 \%$ & 72 & $100 \%$ \\
\hline Two valued term rating & 2 & $10.50 \%$ & 1 & $8.33 \%$ & 1 & $9.09 \%$ & 67 & $93.06 \%$ \\
\hline \multicolumn{9}{|l|}{ Extensional language ratings } \\
\hline Consciousness of projection rating & 18 & $94.73 \%$ & 12 & $100 \%$ & 11 & $100 \%$ & 66 & $93.06 \%$ \\
\hline Comparative language ratings & 19 & $100 \%$ & 11 & $91.66 \%$ & 10 & $90.9 \%$ & 68 & $84.44 \%$ \\
\hline Quantifying language rating & 1 & $5.2 \%$ & 2 & $16.66 \%$ & 2 & $18.18 \%$ & 57 & $79.17 \%$ \\
\hline Conditional language ratings & 19 & $100 \%$ & 12 & $100 \%$ & 11 & $100 \%$ & 72 & $100 \%$ \\
\hline Pseudo quantifying terms & 19 & $100 \%$ & 12 & $100 \%$ & 11 & $100 \%$ & 72 & $100 \%$ \\
\hline
\end{tabular}


Table 6

Number of Sermons Achieving Minimum 50\% Threshold

\begin{tabular}{|c|c|c|c|c|c|c|c|c|}
\hline & \multicolumn{3}{|c|}{ 1960s } & \multicolumn{2}{|l|}{ 1970s } & \multicolumn{2}{|l|}{$1980 \mathrm{~s}$} & \multirow{2}{*}{$\begin{array}{c}\text { 2000s } \\
\text { \%at } 50 \% \\
\text { Level }\end{array}$} \\
\hline & $\mathrm{N}=$ & $\begin{array}{l}\% \text { at } 50 \% \\
\text { Level }\end{array}$ & $\mathrm{N}=$ & $\begin{array}{l}\% \text { at } 50 \% \\
\text { Level }\end{array}$ & $\mathrm{N}=$ & $\begin{array}{l}\% \text { at } 50 \% \\
\text { Level }\end{array}$ & $\mathrm{N}=$ & \\
\hline \multicolumn{9}{|l|}{ Intentional language content } \\
\hline Superlative rating & 69 & $75 \%$ & 63 & $75 \%$ & 44 & $74.57 \%$ & 215 & $71.67 \%$ \\
\hline Identification predication language ratings & 92 & $100 \%$ & 84 & $100 \%$ & 59 & $100 \%$ & 290 & $96.67 \%$ \\
\hline Allness rating & 92 & $100 \%$ & 83 & $98.80 \%$ & 59 & $100 \%$ & 291 & $97 \%$ \\
\hline Two valued term rating & 0 & $0 \%$ & 7 & $8.33 \%$ & 0 & $0 \%$ & 11 & $3.67 \%$ \\
\hline \multicolumn{9}{|l|}{ Extensional language ratings } \\
\hline Consciousness of projection rating & 86 & $93.47 \%$ & 80 & $94.23 \%$ & 56 & $94.91 \%$ & 276 & $92.0 \%$ \\
\hline Comparative language ratings & 87 & $94.56 \%$ & 83 & $98.80 \%$ & 58 & $98.30 \%$ & 271 & $90.33 \%$ \\
\hline Quantifying language rating & 23 & $25 \%$ & 28 & $33.33 \%$ & 7 & $11.86 \%$ & 72 & $24.00 \%$ \\
\hline Conditional ,language ratings & 92 & $100 \%$ & 84 & $100 \%$ & 59 & $100 \%$ & 295 & $98.33 \%$ \\
\hline Pseudo quantifying terms & 89 & $96.73 \%$ & 83 & $98.80 \%$ & 58 & $98.30 \%$ & 286 & $95.33 \%$ \\
\hline
\end{tabular}

Table 7

Detailed "Goodness of Fit" Rates for Sermons Delivered 1920-2010

\begin{tabular}{|c|c|c|c|c|c|c|c|c|}
\hline \multirow[b]{2}{*}{ Intentional language content } & \multicolumn{2}{|c|}{$1920 \mathrm{~s}$} & \multicolumn{2}{|c|}{$1930 \mathrm{~s}$} & \multicolumn{2}{|c|}{ 1940s } & \multicolumn{2}{|c|}{$1950 \mathrm{~s}$} \\
\hline & $\mathrm{N}=$ & $\begin{array}{l}\text { High } \\
\text { low }\end{array}$ & $\mathrm{N}=$ & $\begin{array}{l}\text { High } \\
\text { low }\end{array}$ & $\mathrm{N}=$ & $\begin{array}{l}\text { High } \\
\text { low }\end{array}$ & $\mathrm{N}=$ & $\begin{array}{l}\text { High } \\
\text { low }\end{array}$ \\
\hline Superlative & 0.56 & $0-0.67$ & 0.39 & $0-0.67$ & 0.40 & $0-0.67$ & 0.43 & $0-0.67$ \\
\hline Identification predication language & 100 & & 1.00 & $0-1.00$ & 1.00 & & 1.00 & \\
\hline Allness & 0.78 & $0-0.85$ & 0.82 & $0.68-0.85$ & 0.90 & $0.68-0.87$ & 0.74 & $0.67-0.87$ \\
\hline Two valued term & 0.07 & 0 & 0.05 & $0-0.52$ & 0.06 & $0-0.62$ & 0.04 & \\
\hline \multicolumn{9}{|l|}{ Extensional language ratings } \\
\hline Consciousness of projection & 1.00 & $0-1.00$ & 1.00 & $0-1.00$ & 1.00 & & 0.85 & $0-1.00$ \\
\hline Comparative language & 0.81 & $0.61-0.92$ & 0.73 & $0-0.90$ & 0.90 & $0-90$ & 0.65 & $0.79-0.91$ \\
\hline Quantifying language & 0.04 & $0-0.73$ & & $0-0.76$ & 0.15 & $0-0.76$ & 0.14 & $0-0.78$ \\
\hline Conditional language & 0.83 & $0.80-0.83$ & 0.82 & $0.80-0.83$ & 0.80 & $0.81-0.83$ & 0.73 & $0.68-0.73$ \\
\hline Pseudo quantifying terms & 0.53 & $0.50-0.57$ & 0.52 & $0.5-0.55$ & 0.57 & $0.5-0.53$ & 0.47 & $0.5-0.56$ \\
\hline
\end{tabular}

Table 8

Detailed “Goodness of Fit” Rates for Sermons Delivered 1920-2010

\begin{tabular}{|c|c|c|c|c|c|c|c|c|}
\hline & $1960 s$ & & $1970 \mathrm{~s}$ & & 1980s & & $2000 s$ & \\
\hline Intentional language content & $\mathrm{N}=$ & $\begin{array}{l}\text { High } \\
\text { low }\end{array}$ & $\mathrm{N}=$ & $\begin{array}{l}\text { High } \\
\text { low }\end{array}$ & $\mathrm{N}=$ & $\begin{array}{l}\text { High } \\
\text { low }\end{array}$ & $\mathrm{N}=$ & $\begin{array}{l}\text { High } \\
\text { low } \\
\end{array}$ \\
\hline Superlative rating & 0.51 & $0-0.67$ & 0.52 & $0-0.67$ & 0.51 & $0-0.67$ & 69.38 & $62.02-100$ \\
\hline Identification predication language & 1.00 & & 100 & & 100 & & 100.00 & 100 \\
\hline Allness & 0.84 & $0-0.86$ & 0.84 & $0-0.86$ & 0.81 & $0.67-0.81$ & 80.21 & $67.61-90.7$ \\
\hline Two valued term & 0 & $0-0.62$ & 0.05 & $0-0.62$ & 0 & 0 & 48.28 & $61.11-65.87$ \\
\hline \multicolumn{9}{|l|}{ Extensional language } \\
\hline Consciousness of projection & 0.98 & $0-100$ & 100 & $0-100$ & 100 & $0-100$ & 100.00 & 100 \\
\hline Comparative language & 0.74 & $0-0.91$ & 0.81 & $0-94$ & 0.81 & $0-0.91$ & 78.72 & 67.36-96 \\
\hline Quantifying language & 0.20 & & 0.26 & $0-0.79$ & 0.11 & $0-100$ & 72.26 & 66.97-85.61 \\
\hline Conditional language & 0.83 & $0.69-0.94$ & 0.84 & $0.67-0.86$ & 0.81 & $0.67-0.85$ & 80.54 & $67.52-100$ \\
\hline Pseudo quantifying terms & 0.51 & $0-0.57$ & 0.54 & $0.5-0.56$ & 0.53 & $0.51-0.53$ & 52.69 & $50-64.29$ \\
\hline
\end{tabular}


The results for minimum threshold levels suggest that the balanced rate of use of intentional and extensional language in sermons is consistent from 1920 through 2010. Balance was observed across the use of intentional and extensional language criteria generally. Specifically, the use of Superlative, Identification-Predication, and Allness language was high across the decades. Two exceptions were observed for the use of Superlative language. The use of Two-Valued Term language was consistently low with one exception. The use of Consciousness of Projection, Comparative, Conditional and Pseudo-Quantifying language was high across all decades. The use of Quantifying language was consistently low with one exception.

Three outliers are observed. The use of superlative language in sermons from the 1930s and 1940s was significantly lower than use in other decades. We believe this is a reflection of the limited number of sermons in the data set and not a reliable variation. In addition, the rate of use of Two-Valued terms was significantly higher for sermons from the 1950s. This result requires further investigation. It may be a reflection of the increased focus on post-war scientific and engineering perspective. Similarly, the rate of use of quantifying language was similarly high for sermons from the 1950s. This also requires further investigation to determine whether it reflects a post-war perspective.

\section{Expected Results for Questions 2 and 3}

We expect to be able to detect the emotional intensity of sermons using the Gottschalk-Gleser metrics. Furthermore, we expect the emotional intensity of sermons will remain consistent across the decades.

The rate of emotional intensity was a new criteria introduced for analysis against the data set of historical sermons. The criteria were not retrospectively applied to the data set for 2000-2010. Results are considered in terms of their variability over the six historical decades in which the sermons were delivered.

Research results suggest that it is possible to measure the emotional intensity of sermons (Table9,Table10). The results further suggest that different aspects of emotion rate differently when applied to sermon content. The level of anxiety expressed in sermon content ranges from very high in the 1920s and 1930s, to moderately high from the 1940s through the 1970s. The level of anxiety appears to decline to slightly high in the 1980s. This result is worthy of further future investigations. In addition to a case by case review of the concepts and their frequency in individual sermons, future investigation may also consider whether the current anxiety profile should be updated based on use in a new discipline——religious studies.

Table 9

Results for Emotional Indicators

\begin{tabular}{|c|c|c|c|c|c|c|c|c|}
\hline & \multicolumn{2}{|r|}{$1920 \mathrm{~s}$} & \multicolumn{2}{|r|}{$1930 \mathrm{~s}$} & \multicolumn{2}{|r|}{$1940 \mathrm{~s}$} & \multicolumn{2}{|r|}{ 1950s } \\
\hline & Ave. & Rating & Ave. & Rating & Ave. & Rating & Ave. & Rating \\
\hline Total anxiety & 3.61 & Very high & 3.57 & Very high & 2.76 & Moderately high & 2.28 & Moderately high \\
\hline Hostility outward facing & 1.88 & Slightly high & 2.01 & Slightly high & 1.62 & Slightly high & 1.29 & Slightly high \\
\hline Hostility inward facing & 2.46 & Moderately high & 2.52 & Moderately high & 1.07 & Slightly high & 1.49 & Slightly high \\
\hline Hope & 0.47 & Normal & 0.2 & Normal & 0.27 & Normal & 1.1 & Slightly high \\
\hline
\end{tabular}

Table 10

Results for Emotional Indicators

\begin{tabular}{lllllll}
\hline & \multicolumn{1}{c}{ 1960s } & & 1970s & \multicolumn{1}{c}{ 1980s } \\
\hline & Ave. & Rating & Ave. & Rating & Ave. & Rating \\
\hline Total anxiety & 2.35 & Moderately high & 2.89 & Moderately high & 1.56 & Slightly high \\
Hostility outward facing & 1.34 & Slightly high & 1.6 & Slightly high & 0.92 & Normal \\
Hostility inward facing & 1.56 & Slightly high & 1.9 & Slightly high & 0.93 & Normal \\
Hope & 0.43 & Normal & 0.75 & Normal & 0.81 & Normal \\
\hline
\end{tabular}


Results of the semantic analysis of the level emotion associated with the Hostility Outward Facing factor in sermons range from normal to slightly high. Results of the semantic analysis of the level of emotion associated with Hostility Inward Facing factor in sermons ranges from normal to moderately high. The higher rate registered for the 1920s and 1930s may be an outlier associated with the data set. Testing against a larger data set for these decades will illustrate whether this is a reflection of the limited number of sermons or is a reflection of preaching styles exhibited by the individuals whose sermons were included in the data set for those decades.

The most interesting result for the Emotional Intensity metrics, though, pertains to Hope. There are clear variations in results across the decades for the intensity of Hope in sermons. The lowest rate - a negative rate which reflects below normal intensity - is observed for sermons from the 1940s. The 1920s and the 1960s eras of prosperity and well-being - register higher rates of hope. The intensity of Hope, though, appears to be increasing towards the end of the 20th century. The rates for the 1970s and 1980s are from two to four times greater than for the earlier decades. This result is worthy of further investigation, both at the individual sermon level and at the individual concept level. In addition, the use of the Gottschalk Gleser models should be extended to sermons delivered in the 1990s and 2000s to determine whether the trend continues or reverses.

The significance of this research is the reinforcement of balance in the use of intentional and extensional language in sermons — now observed across the 20th and 21st centuries. The most plausible explanation for this derives from the field of knowledge sciences. Christian sermons are grounded in the fundamental knowledge base of the religion. Clergy learn how to design and deliver sermons to ensure effective transfer and mobilization of religious knowledge. The larger implication is that the field of religious studies is an important one for further study of knowledge sciences, in particular knowledge transfer in well established disciplines. As evidence of this, the language profile first used in 2011 was successfully applied to human resource management and to intellectual capital management applications in the corporate and international development sectors. We further demonstrated that it is possible to successfully apply to religious content semantic profiles developed in other fields such as psychology and psychiatry.

A key observation, though, pertains to the challenges involved in finding and preserving religious sermons. These are key sources of information in religious studies which should be preserved and made publicly available. More affordable and widely accessible digitization methods will mitigate this challenge in the future.

\section{References}

Bedford, D. A. D. (2011).Using semantic technologies to analyze the semantic orientation of religious sermons-A validation of the early work of McLaughlin. Advances in the Study of Information and Religion.

Boder, D. P. (1940) .The adjective-verb quotient; A contribution to the psychology of language. The Psychological Record, 3, 310-343.

Busemann, A. (1925). Die Sprache der Jugend als Ausdruck der Entwicklungs-rhthmic. Fischer, Jena.

Gleser, G. C., Gottschalk, L. A., \& Springer, K. J. (1961). An anxiety scale applicable to verbal samples. Archives of General Psychiatry, 5, 593-605.

Gleser, G. C., Winget, C. N., \& Seligman, R. (1979). Content scaling of affect in adolescent speech samples. Journal of Youth and Adolescence, 8, 282-297.

Gottschalk, L. A., \& G. Hambridge, Jr. (1955). Verbal behavior analysis: A systematic approach to the problem of quantifying psychological processes. Journal of Project Technologies, 19, 387-409.

Gottschalk, L. A., Gleser, G. C., \& Springer, K. J. (1963). Three hostility scales applicable to verbal samples. Archives of General Psychiatry, 9, 254-279. 
Gottschalk, L. A., \& Gleser, G. C. (1969). The measurement of psychological states through the content analysis of verbal behavior. University of California Press.

Gottschalk, L. A. (1974). A hope scale applicable to verbal samples. Archives of General Psychiatry, 7, 489-496.

Gottschalk, L. A. (1974). The application of a method of content analysis to psychotherapy research. American Journal of Psychotherapy, 28, 488-499.

Gottschalk, L. A. (1982). Manual of uses and applications of the Gottschalk-Gleser verbal behavior scales. Research Communications in Psychology, Psychiatry and Behavior, 7, 273-327.

Gottschalk, L. A. (1995). Content analysis of verbal behavior - New findings and clinical applications. Lawrence Erlbaum Associates, Hillsdale New Jersey.

Gottschalk, L. A. (1999). The application of a computerized measurement of the content analysis of natural language to the measurement of the effects of psychoactive drugs. Methods and Findings in Experimental and Clinical Pharmacology, 21, 133-138.

Gottschalk, L. A., \& Bechtel, R. J. (1982). The measurement of anxiety through the computer analysis of verbal samples. Comprehensive Psychiatry, 23, 364-369.

Gottschalk, L. A. \& Bechtel, R. J. (1989). Artificial intelligence and the computerization of the content analysis of natural language. Artificial Intelligence in Medicine, 1, 131-137.

Gottschalk, L. A. \& Bechtel, R. J. (1995).Computerized measurement of the content analysis of language. Computer Methods and Programs in Biomedicine, 47, 123-130.

Gottschalk, L. A. \& Frank, E. C. (1967). Estimating the magnitude of anxiety from speech. Behavioral Science , 12, $289-295$.

Gottschalk, L. A., Gleser, G. C., \& Springer, K. J. (1963). Three hostility scales applicable to verbal samples. Archives of General Psychiatry, 9, 254-279.

Gottschalk, L. A., Hausmann, C., \& Brown, J. S. (1975). A computerized scoring system for use with content analysis scales. Comprehensive Psychiatry, 16, 77-90.

Janis, I. L. (1949). The problem of validating content analysis. In H. D. Lasswell and N. C. Leites. George Steward (Ed.), The language of politics: Studies in quantitative semantics (pp. 55-82). New York.

Kaplan, A. (1943). Content analysis and the theory of signs. Philosophy of Science, 10, 230-247.

Korzybski, A. (1938). Outline of general semantics. General Semantics Papers from the First American Congress for General Semantics. New York.

Malla, A. K., Kazarian, S. S., \& Barnes, S. (1991). Validation of the five minute speech sample in measuring expressed emotion. Canadian Journal of Psychiatry, 376, 297-299.

McLaughlin, R. W. (1940). Intentional-extensional language as a measure of semantic orientation. Bulletin of the Evangelical Theological Society, 143-151.

Ortberg, J. (2007). Birthing a sermon: A step-by-step guide to bringing the text alive. Leadership Journal.

Viney, L. L. (1981). Content analysis: A research tool for community psychologists. American Journal of Community Psychology, 9, 269-281

Viney, L. L. (1983). Assessment of psychological states through content analysis of verbal communications. Psychological Bulletin, 94, 542-563. 